\title{
High-Efficiency, Vacuum-Deposited, Small-Molecule Organic Tandem and Triple-Junction Photovoltaic Cells
}

\author{
Xiaozhou Che, Xin Xiao, Jeramy D. Zimmerman, Dejiu Fan, and Stephen R. Forrest*
}

Organic photovoltaics (OPVs) offer a low-cost, light-weight, and mechanically flexible route to solar energy conversion. ${ }^{[1-4]}$ Compared with polymers, small molecule OPVs share the advantages of using materials with well-defined molecular structures and weights. Hence, they provide a simple pathway for purification, and are compatible with deposition of multiple layers using highly controlled thermal evaporation without concern for dissolving (and hence damaging) previously deposited layers or sub-cells. ${ }^{[5-7]}$ Single-junction small molecule OPVs have achieved a power conversion efficiency of $>8 \%,{ }^{[8-11]}$ but the narrow absorption range, low open-circuit voltages $\left(V_{\mathrm{OC}}\right)$ and large thermalization energy losses at short wavelengths ultimately limit the power conversion efficiencies of single element OPVs. ${ }^{[2,13]}$ This shortcoming has led to investigation of multijunction OPVs, ${ }^{14-17]}$ whose design can allow for more complete coverage of the solar spectrum while maintaining a high $V_{\mathrm{OC}}$. For example, polymer tandem (i.e., double element) photovoltaic cells have already demonstrated a power conversion efficiency of $\eta_{\mathrm{P}}=10.6 \% .^{[18]}$ Recently Heliatek announced a $12 \%$ efficient tandem OPV $^{[19]}$ although no details of the structure or measurement are available. Progress on multijunction OPVs has therefore been rapid, indicating considerable potential for further improvement.

Tandem structures deliver high efficiency since the sub-cells are thin to accommodate the short exciton diffusion length (where $L_{\mathrm{D}} \approx 10 \mathrm{~nm}$ ) characteristic of the organic active region, but as a result they are also semitransparent. To mitigate the problem of a short diffusion length, vacuum deposited planarmixed heterojunction (PM-HJ) active regions have been used in which the donor and acceptor molecules are mixed in the active region. The PM-HJ is not limited by $L_{\mathrm{D}}$, but rather the much larger "charge collection length". ${ }^{20,21]}$ Therefore, the photoactive region can be made thicker to enhance optical absorption without compromising cell efficiency. To further improve the

X. Che, Prof. S. R. Forrest Applied Physics Program

University of Michigan

Ann Arbor, MI 48109, USA

E-mail: stevefor@umich.edu

X. Xiao, Dr. J. D. Zimmerman, D. Fan, Prof. S. R. Forrest

Department of Electrical Engineering and Computer Science

University of Michigan

Ann Arbor, MI 48109, USA

Prof. S. R. Forrest

Departments of Physics and Department of Materials Science

and Engineering

University of Michigan

Ann Arbor, MI 48109, USA

DOI: 10.1002/aenm.201400568 charge collection efficiency while maintaining a high absorption, the PM-HJ also employs a neat (homogenous) donor and/ or acceptor layer, whose thicknesses are comparable to $L_{\mathrm{D}}$ and that clad the mixed region.

Unfortunately, such thick and highly absorbing sub-cells typically result in spectral overlaps between elements in the tandem that prevent photons from reaching the back sub-cell, ultimately limiting the total photocurrent. In this work, we overcome this deficiency by using two relatively thick and strongly absorbing, vacuum-deposited small molecule PM-HJ sub-cells with considerable separation between their absorption maxima, thereby minimizing spectral overlap and maximizing photocurrent. ${ }^{[22]}$ The front sub-cell adjacent to the transparent anode comprises the primarily orange-to-near infrared (NIR) absorbing donor, 2-((7-(5-(dip-tolylamino)thiophen-2-yl)benzo[c][1,2,5]thiadiazol4-yl)methylene)malononitrile (DTDCTB) ${ }^{[23-25]}$ blended with $\mathrm{C}_{60}$, paired with an ultraviolet-to-yellow absorbing $\mathrm{DBP}: \mathrm{C}_{70}$ back sub-cell. In the front cell, the $\mathrm{C}_{60}$ intermolecular charge transfer $(\mathrm{CT})$ absorption feature in the green is greatly reduced when diluted in DTDCTB, ${ }^{[26]}$ thus providing a spectrally complementary system with the back sub-cell. The tandem solar cell broadly covers the solar spectrum from $\lambda=350 \mathrm{~nm}$ to $900 \mathrm{~nm}$, achieving an efficiency of $10.0 \pm 0.2 \%$ under 1 sun, AM $1.5 \mathrm{G}$ illumination $\left(25 \pm 1{ }^{\circ} \mathrm{C}, 1000 \mathrm{~W}-\mathrm{m}^{-2}\right.$, ASTM G173-03).

To further improve the cell performance, a second DBP: $\mathrm{C}_{70}$ sub-cell is placed immediately adjacent to the transparent anode at the second order optical interference maximum to form a triple-junction OPV. The cell exhibits a power conversion efficiency of $11.1 \pm 0.2 \%$, with $V_{\mathrm{OC}}$ of $2.58 \pm 0.01 \mathrm{~V}$ and the external quantum efficiency (EQE) close to $100 \%$ at short wavelengths. Further, this cell employs a thick stack structure that exploits the second order optical interference maximum. Together with a nearly optically lossless BPhen: $\mathrm{C}_{60}$ electron filtering layer connecting the sub-cells, our design approach can lead to achieving even higher efficiencies in the future.

The low band gap DTDCTB absorbs at wavelengths as long as $\lambda=900 \mathrm{~nm}$. To separate the front (i.e., that nearest the anode) and the back sub-cell (nearest the cathode) absorption spectra, the blue-green absorbing $\mathrm{C}_{60}$ is used in the front cells as the acceptor, whereas the broadly absorbing $\mathrm{C}_{70}$ is employed solely in the back sub-cell. The extinction coefficients $(k)$ of the DTDCTB: $\mathrm{C}_{60}$ films measured as functions of volume ratio are shown in Figure 1a. The absorption of a neat $\mathrm{C}_{70}$ film is also shown for comparison. The DTDCTB exhibits an absorption peak at $\lambda=700 \mathrm{~nm}$, while $\mathrm{C}_{60}$ shows two peaks at $\lambda=360 \mathrm{~nm}$ and $\lambda=450 \mathrm{~nm}$, corresponding to Frenkel-type and intermolecular CT excitations. ${ }^{[27]}$ The CT feature results from electrons excited from the highest occupied molecular orbital of one molecule to the lowest unoccupied molecular orbital of a nearby $\mathrm{C}_{60}$ molecule, and hence is sensitive to $\mathrm{C}_{60}$ concentration. In 

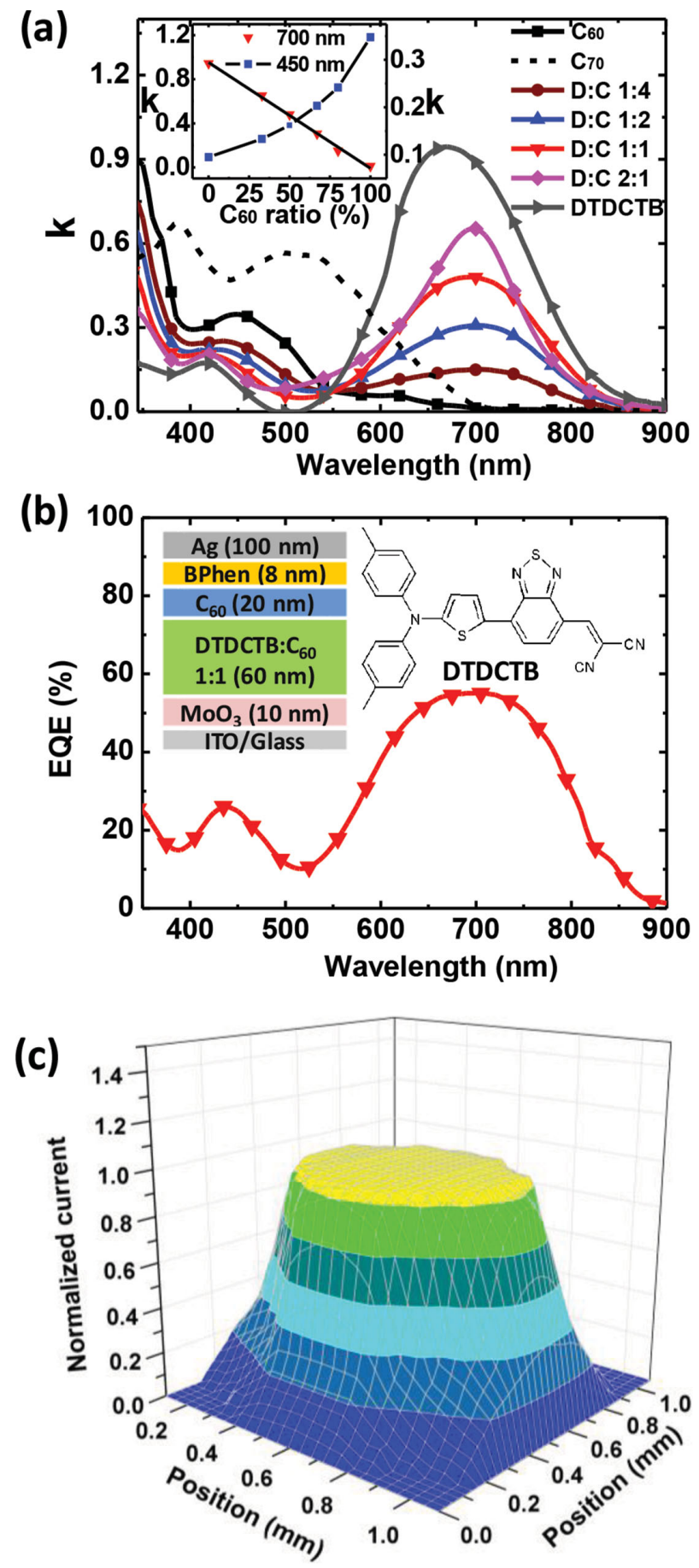

Figure 1. a) Extinction coefficient ( $k$ ) of DTDCTB: $\mathrm{C}_{60}$ films with different ratios of DTDCTB and $C_{60}$, along with $k$ for neat $C_{60}, C_{70}$, and DTDCTB neat layers. b) External quantum efficiency $(E Q E)$ of the single junction DTDCTB: $C_{60}$ cell. Inset: Schematic of the single junction DTDCTB: $C_{60}$ cell and the DTDCTB molecular structure. c) Normalized 2D responsivity map of a $1 \mathrm{~mm}$ diameter circular device at a wavelength of $500 \mathrm{~nm}$.

contrast, the intramolecular Frenkel transition absorption strength is linearly proportional to the molecular concentration. To analyze the Frenkel and CT absorption in the DTDCTB: $\mathrm{C}_{60}$ mixed film, $k$ at $\lambda=450 \mathrm{~nm}$ and $\lambda=700 \mathrm{~nm}$ as a function of the
$\mathrm{C}_{60}$ percentage is plotted in the inset of Figure 1a. The DTDCTB Frenkel absorption peak at $\lambda=700 \mathrm{~nm}$ linearly decreases with $\mathrm{C}_{60}$ concentration, as expected. On the other hand, the $\mathrm{C}_{60} \mathrm{CT}$ peak at $\lambda=450 \mathrm{~nm}$ is significantly reduced even at a modest dilution, eliminating losses caused by absorption in the green.

An optimized DTDCTB: $\mathrm{C}_{60}$ single junction photovoltaic cell has the following structure shown in Figure $1 \mathrm{~b}$ inset: ITO/ $\mathrm{MoO}_{3}$ $(10 \mathrm{~nm}) /$ DTDCTB: $_{60}(60 \mathrm{~nm}, 1: 1$ ratio by vol. $) / \mathrm{C}_{60}(20 \mathrm{~nm}) /$ Bathophenanthroline (BPhen, $8 \mathrm{~nm}) / \mathrm{Ag}(100 \mathrm{~nm})$. The $\mathrm{MoO}_{3}$ serves as the anode buffer layer due to its large work function, high transmittance, and low resistance, ${ }^{[28]}$ and BPhen is used as the exciton blocking buffer layer adjacent to the cathode. ${ }^{[29]}$ The device exhibits $V_{\mathrm{OC}}=0.82 \pm 0.01 \mathrm{~V}$, short-circuit current density, $J_{\mathrm{SC}}=11.6 \pm 0.2 \mathrm{~mA} \mathrm{~cm}{ }^{-2}$ (spectral mismatch factor of $M=1.09 \pm 0.02$ ), and fill factor $F F=0.55 \pm 0.01$. This corresponds to a power conversion efficiency of $5.3 \pm 0.1 \%$ at 1 sun, AM 1.5G illumination. At this blend ratio, the CT absorption by $\mathrm{C}_{60}$ is suppressed to only $40 \%$ of its value in the neat film. Accordingly, the DTDCTB: $\mathrm{C}_{60}$ cell shows an external quantum efficiency of $E Q E>55 \%$ at $\lambda=700 \mathrm{~nm}$, falling off to $<25 \%$ at $\lambda<500 \mathrm{~nm}$ (Figure 1b). As shown below, this NIR absorbing front sub-cell has minimal spectral overlap with the principally green-absorbing DBP: $\mathrm{C}_{70}$ back sub-cell.

We tested the photoresponse uniformity of $1 \mathrm{~mm}$ diameter devices by scanning an optical fiber across the device (see Experimental Section), with the resulting profile shown in Figure 1c. The current is uniform across the device and falls off sharply at the edge, indicating there are no observable edge efficiency enhancements or other response artifacts, even for small diameter devices.

To optimize the sub-cells used in the tandem shown in Figure 2a, we fabricated a single junction front-only cell approximating the DTDCTB: $\mathrm{C}_{60}$ sub-cell by inserting a $0.1 \mathrm{~nm}$ thick $\mathrm{Ag}$ nanoparticle layer (used for charge recombination and plasmonic field enhancement) ${ }^{[30]}$ followed by a $40 \mathrm{~nm}$ thick $\mathrm{MoO}_{3}$ spacer located beneath the Ag contact. ${ }^{[31]}$ Compared with the optimized single junction cell, the thickness of the neat $\mathrm{C}_{60}$ layer was reduced from $20 \mathrm{~nm}$ to $5 \mathrm{~nm}$ to move the front cell closer to the cathode to increase the absorption by the active DTDCTB: $\mathrm{C}_{60}$ layer, and to reduce the CT absorption of the $\mathrm{C}_{60}$ layer. The optimized structure of the back sub-cell is: $\mathrm{ITO} / \mathrm{MoO}_{3}$ $(5 \mathrm{~nm}) / \mathrm{DBP}: \mathrm{C}_{70}(30 \mathrm{~nm}, 1: 10$ ratio by vol. $) / \mathrm{C}_{70}(7 \mathrm{~nm}) / \mathrm{BPhen}$ $(7 \mathrm{~nm}) / \mathrm{Ag}(100 \mathrm{~nm})$, resulting in $J_{\mathrm{SC}}=11.3 \pm 0.2 \mathrm{~mA} \mathrm{~cm}{ }^{-2}$ $(M=1.00 \pm 0.01), V_{\mathrm{OC}}=0.90 \pm 0.01 \mathrm{~V}, F F=0.61 \pm 0.01$ and $\eta_{\mathrm{P}}=$ $6.2 \pm 0.1 \%$, comparable to that of the front sub-cell.

The extinction coefficient of the $1: 1$ DTDCTB: $\mathrm{C}_{60}$ and the 1:10 DBP: $\mathrm{C}_{70}$ blends along with the AM $1.5 \mathrm{G}$ solar spectrum, ${ }^{[32]}$ are shown in Figure $2 \mathrm{~b}$. The $\mathrm{DBP}: \mathrm{C}_{70}$ film exhibits a broad spectral response at $\lambda<700 \mathrm{~nm}$, while the DTDCTB: $\mathrm{C}_{60}$ layer primarily absorbs from $\lambda=500 \mathrm{~nm}$ to $900 \mathrm{~nm}$. By stacking these two sub-cells, absorption spans the wavelengths from $\lambda$ $=350 \mathrm{~nm}$ to $900 \mathrm{~nm}$, thereby covering a large portion of solar spectrum with only minimal overlap between the constituent devices. The tandem thus harvests light efficiently with good current match between the sub-cells.

Figure 2c shows the EQE spectrum of the tandem OPV with the commonly used 3,4,9,10-perylenetetracarboxylic-bisbenzimidazole (PTCBI) interconnecting layer ${ }^{[22,31,33,34]}$ between the front and back sub-cells. The EQE of the tandem cell is calculated 

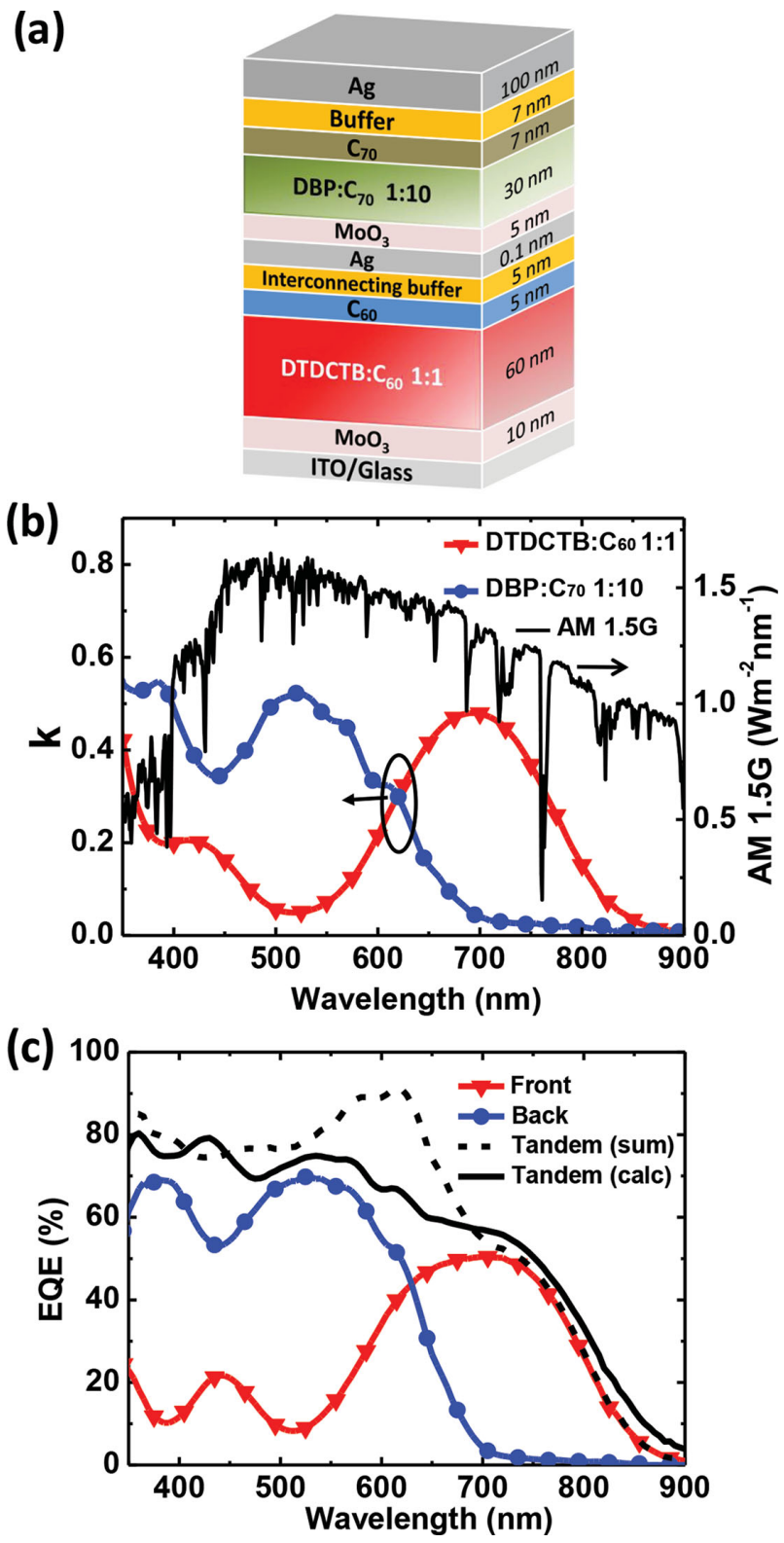

Figure 2. a) Schematic of the tandem organic photovoltaic cell comprised of DTDCTB: $\mathrm{C}_{60}$ and DBP: $\mathrm{C}_{70}$ sub-cells. b) Extinction coefficients, $k$, of the two mixed absorbers: the front cell DTDCTB: $C_{60}$ (1:1 by vol.), and the back cell DBP: $C_{70}(1: 10)$. Also shown is the AM 1.5C solar spectrum. c) $E Q E$ of the measured front-only cell (inverted triangles), back-only cell (circles), the sum of the two (dashed line), and the calculated EQE of the tandem cell structure (solid line) shown in a), with PTCBI as the interconnecting buffer layer.

(solid line) based on the model of Lassiter et al., ${ }^{[31,35]}$ along with the sum of the measured EQE of the sub-cells (dashed line). The tandem cell EQE is higher than that measured for both individual component sub-cells, and is nearly identical with the sum of these efficiencies, except for $<10 \%$ loss between $\lambda=$ $550 \mathrm{~nm}$ and $700 \mathrm{~nm}$ where the sub-cells show a small absorption overlap. The tandem device performance parameters are $J_{\mathrm{SC}}=9.2 \pm 0.2 \mathrm{~mA} \mathrm{~cm}^{-2}(M=0.96 \pm 0.01), V_{\mathrm{OC}}=1.72 \pm 0.01 \mathrm{~V}$, $F F=0.58 \pm 0.01$, giving $\eta_{\mathrm{P}}=9.2 \pm 0.2 \%$. (a)

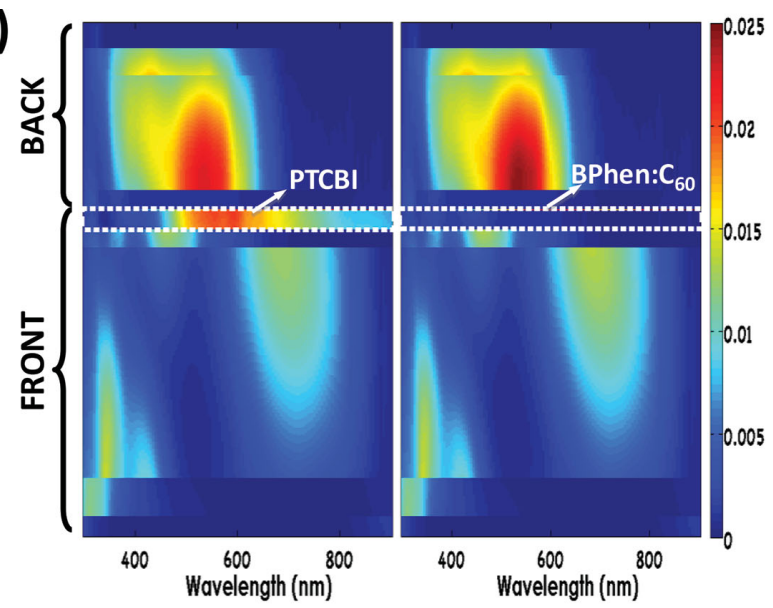

(b)

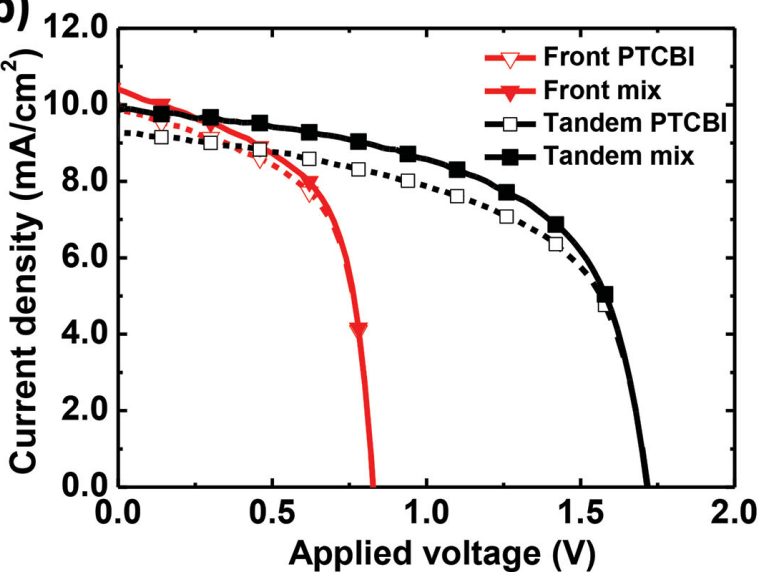

Figure 3. a) Simulated optical field distributions in the tandem cell with PTCBI or BPhen: $\mathrm{C}_{60}$ as the interconnecting buffer layer. b) Current density-voltage $(U-V)$ characteristics of the front-only and the tandem cell with these two interconnecting buffer layers.

In spite of its high conductivity, interconnecting layers with a PTCBI blocker have a significant absorption loss in the visible. Hence, for cell interconnection, we employed a previously reported transparent exciton blocking and electron conducting BPhen: $\mathrm{C}_{60}$ electron filter. ${ }^{[26,36]}$ Figure $3 \mathrm{a}$ shows the simulated optical field distribution within the tandem cell, comparing a $5 \mathrm{~nm}$ thick PTCBI with a similarly thick BPhen: $\mathrm{C}_{60}$ mixed buffer. As the dashed white rectangle indicates, the BPhen: $\mathrm{C}_{60}$ is transparent, in striking contrast with the PTCBI buffer. The simulation also shows that both sub-cells fit within the first interference maximum of the optical field.

The fourth quadrant $J-V$ characteristics of tandems utilizing these two interconnecting layers are shown in Figure 3b. As expected, when PTCBI is replaced with BPhen: $\mathrm{C}_{60}, J_{\mathrm{SC}}$ increases from $9.9 \pm 0.2 \mathrm{~mA} \mathrm{~cm}{ }^{-2}$ to $10.4 \pm 0.2 \mathrm{~mA} \mathrm{~cm}{ }^{-2}$ in the front sub-cell, with no significant change in FF. Hence, the efficiency of the front sub-cell increases from $4.8 \pm 0.1 \%$ to $5.1 \pm 0.1 \%$. Also from Figure $3 \mathrm{a}$, the optical field in the DBP: $\mathrm{C}_{70}$ sub-cell is enhanced when using BPhen: $\mathrm{C}_{60}$, leading to a corresponding increase in current. Consequently, $J_{\mathrm{SC}}$ of the tandem cell is increased to $9.9 \pm 0.2 \mathrm{~mA} \mathrm{~cm}{ }^{-2}$, which shows significant improvement over previously reported small molecule tandem 
Table 1. Measured (meas) and calculated (calc) tandem sub-cells, tandem cell and triple-junction cell performances.

\begin{tabular}{lccccc}
\hline Cells $^{\mathrm{a})}$ & $\begin{array}{c}J_{\mathrm{SC}} \\
{\left[\mathrm{mA} \mathrm{cm}^{-2}\right]}\end{array}$ & $\begin{array}{c}V_{\mathrm{OC}} \\
{[\mathrm{V}]}\end{array}$ & $F F$ & $\begin{array}{c}\eta_{\mathrm{P}} \\
{[\%]}\end{array}$ & $M$ \\
\hline Front (meas) & $10.4 \pm 0.2$ & $0.82 \pm 0.01$ & $0.59 \pm 0.01$ & $5.1 \pm 0.1$ & $1.09 \pm 0.02$ \\
Front (calc) & 10.0 & 0.82 & 0.57 & 4.7 & - \\
Back (meas) & $11.3 \pm 0.2$ & $0.90 \pm 0.01$ & $0.61 \pm 0.01$ & $6.2 \pm 0.1$ & $1.00 \pm 0.01$ \\
Back (calc) & 9.4 & 0.90 & 0.61 & 5.2 & - \\
Tandem (meas) & $9.9 \pm 0.2$ & $1.72 \pm 0.01$ & $0.59 \pm 0.01$ & $10.0 \pm 0.2$ & $0.95 \pm 0.01$ \\
Tandem (calc) & 9.6 & 1.72 & 0.60 & 9.9 & - \\
Triple (meas) & $7.3 \pm 0.2$ & $2.58 \pm 0.01$ & $0.59 \pm 0.02$ & $11.1 \pm 0.2$ & $0.97 \pm 0.01$ \\
Triple (calc) & 7.7 & 2.62 & 0.61 & 12.3 & - \\
\hline
\end{tabular}

a) Front refers to the planar-mixed heterojunction (PM-HJ) DTDCTB: $\mathrm{C}_{60}$ sub-cell nearest the anode in the tandem; Back refers to the PM-HJ DBP: $\mathrm{C}_{70}$ sub-cell near the cathode in the tandem; Tandem employs a $B$ Phen: $C_{60}$ interconnecting buffer layer; Triple employs a second DBP: $\mathrm{C}_{70}$ sub-cell as the front cell in additional to the tandem structure. Measured $J_{\mathrm{SC}}$ and $\eta_{\mathrm{P}}$ are spectrally corrected. Errors indicate device-to-device variations of samples produced in the same growth cycle; an additional $\approx 5 \%$ of systematic error applies to $J_{\mathrm{SC}}$ and $\eta_{\mathrm{P}}$

cells. ${ }^{[22,34,37]}$ The results of the cell using BPhen: $\mathrm{C}_{60}$ along with $\mathrm{Ag}$ nanoparticles as the interconnecting layer whose structure and optimized layers thicknesses are shown in Figure 2a, are summarized in Table 1.

The optimized tandem cell EQE shown in Figure 4a is similar to that employing a conventional PTCBI buffer, while the measured front sub-cell peak EQE increased. Figure $4 \mathrm{~b}$ shows measured and calculated $4^{\text {th }}$ quadrant $J-V$ characteristics. The calculated tandem $J-V$ characteristics agree with the measurement, suggesting that the models of optical field distribution and charge collection are predictive of performance, thereby simplifying device layer thickness design. The optimized tandem OPV cell achieves a measured $J_{\mathrm{SC}}=9.9 \pm 0.2 \mathrm{~mA} \mathrm{~cm}{ }^{-2}$ $(M=0.95 \pm 0.01), V_{\mathrm{OC}}=1.72 \pm 0.01 \mathrm{~V}, F F=0.59 \pm 0.01$, with $\eta_{\mathrm{P}}=10.0 \pm 0.2 \%$. This represents a $>60 \%$ improvement over the discrete cell efficiencies comprising the stack. Furthermore, the tandem $V_{\mathrm{OC}}$ is equal to the sum of the constituent sub-cells, suggesting that the interconnecting charge recombination layer is lossless.

To take further advantage of the optical field distribution and achieve even higher $V_{\mathrm{OC}}$, an additional DBP: $\mathrm{C}_{70}(1: 10) \mathrm{sub}$ cell is inserted as the front cell in the stack. Figure 5a shows the structure of the triple-junction cell, where the middle DTDCTB: $\mathrm{C}_{60}(1: 1)$ cell is sandwiched between two DBP: $\mathrm{C}_{70}$ (1:10) sub-cells. The BPhen: $\mathrm{C}_{60}$ interconnecting layers are used between the sub-cells to ensure minimal absorption loss. Compared with the tandem cell, the thicknesses of the back DBP: $\mathrm{C}_{70}$ and the middle DTDCTB: $\mathrm{C}_{60}$ cells are increased such that the front, short-wavelength absorbing $\mathrm{DBP}: \mathrm{C}_{70}$ sub-cell fits into the second order optical interference maximum, as shown in Figure 5b. The front and back green-absorbing cells absorb at different optical maxima to efficiently harvest short wavelength photons while complementing the absorption of the middle NIR-absorbing cell. Similar to the tandem cell, the thicknesses of each active layer is optimized by simulation to achieve current balance between sub-cells at 1 sun intensity.
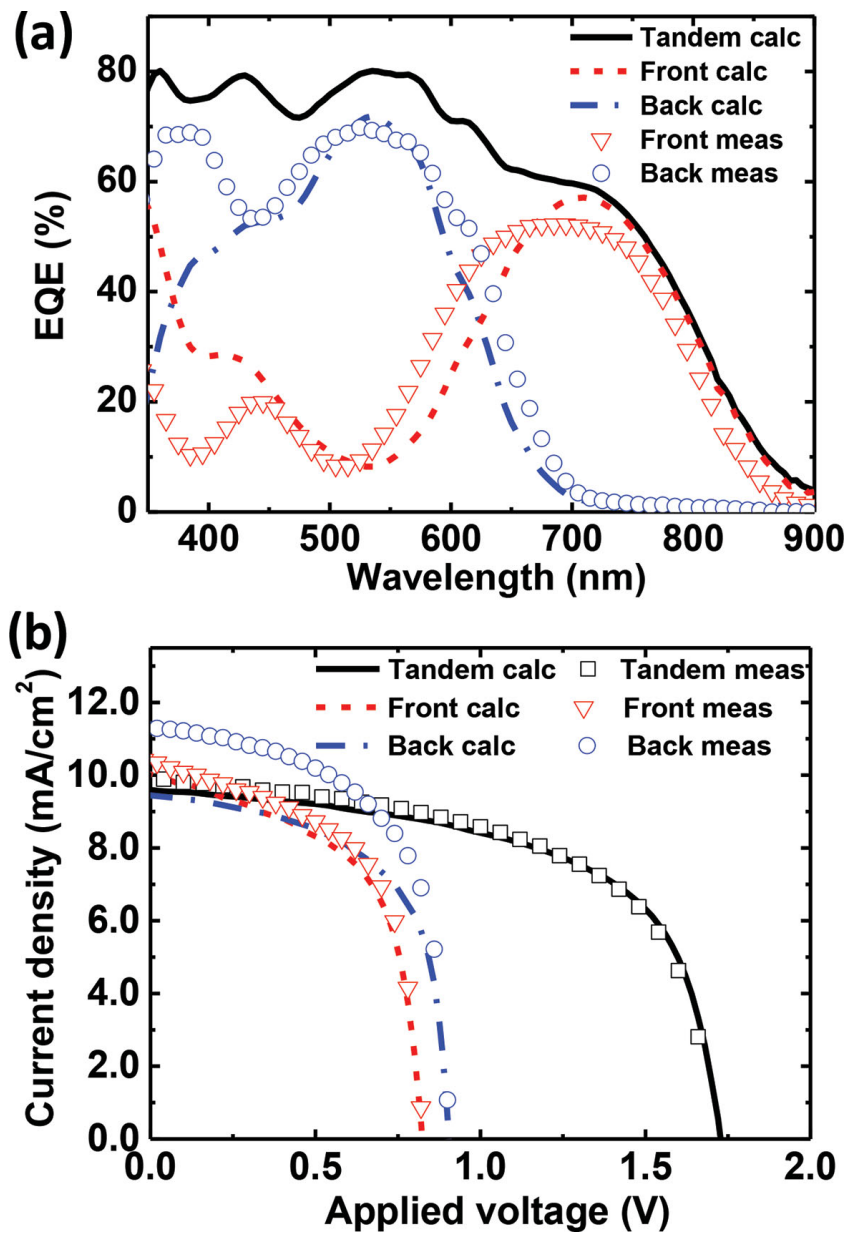

Figure 4. The optimized tandem cell performance: a) Calculated (lines) and measured (dots) EQE of the front (dash; triangle), back (dash-dot; circle) and tandem cell (solid line) using BPhen: $\mathrm{C}_{60}$ as the interconnecting buffer layer; b) Measured $4^{\text {th }}$ quadrant $J-V$ characteristics for the device in (a). Experimental and calculated sub-cell and tandem J-V data were obtained under 1 sun, AM 1.5G illumination.

The $J-V$ characteristics of the triple-junction and tandem cells are compared in Figure 5c, with performance parameters listed in Table 1. Compared with the tandem, the $V_{\mathrm{OC}}$ increases to $2.58 \pm 0.01 \mathrm{~V}$. Although $J_{\mathrm{SC}}$ decreases to $7.3 \pm 0.2 \mathrm{~mA} \mathrm{~cm}^{-2}$, the power conversion efficiency achieved is $\eta_{\mathrm{P}}=11.1 \pm 0.2 \%$. Figure $5 c$, inset, shows that the calculated quantum efficiency at wavelengths from $400 \mathrm{~nm}$ to $700 \mathrm{~nm}$ approaches $100 \%$ in the triple-junction cell due to contributions from the two DBP: $\mathrm{C}_{70}$ sub-cells at the different interference maxima. Note that its $V_{\mathrm{OC}}$ is $0.04 \mathrm{~V}$ lower than the sum of its sub-cells, mainly due to the reduced optical intensity in each active layer.

Lassiter et al. showed that an optimized multijunction structure employs sub-cells whose currents are matched at the maximum power point (MPP) of operation. ${ }^{[35]}$ They defined $\Delta \eta$ as the power conversion efficiency penalty that is related to the mismatch in constituent sub-cell current densities at their MPPs. That is, the optimal design corresponds to $\Delta \eta \rightarrow 0$, where:

$$
\Delta \eta=1-\frac{J_{M M} V_{M M}}{J_{M 1} V J_{M 1}+J_{M 2} V_{M 2}+\ldots+J_{M n} V_{M n}} .
$$


(a)

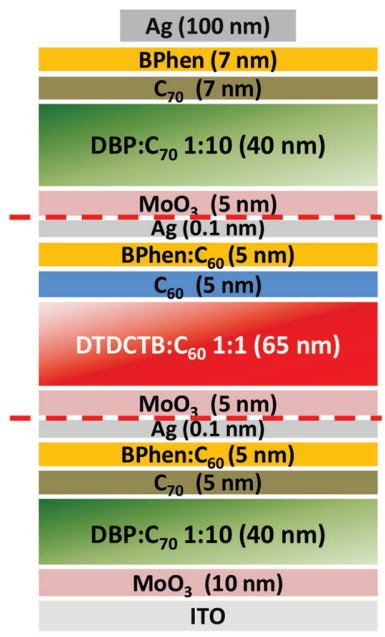

(b)

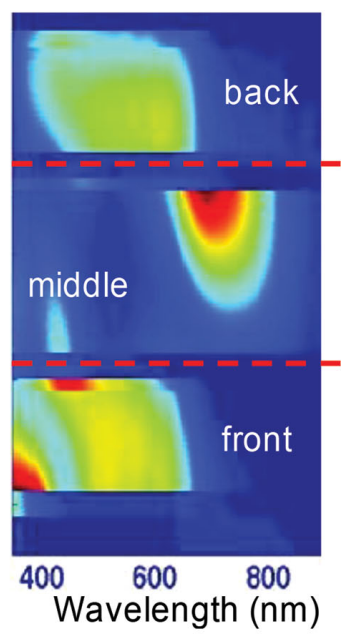

(c)

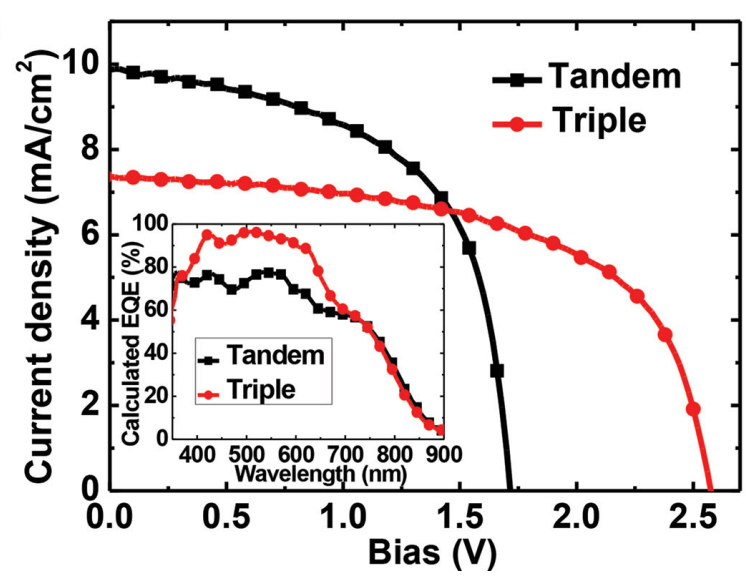

Figure 5. Triple-junction cell: a) device structure schematic and b) optical field distribution of the three sub-cells in the stack. c) Measured $4^{\text {th }}$ quadrant $J-V$ characteristics of the optimized tandem and triple-junction cells ( 1 sun, AM 1.5C illumination, $25 \pm 1^{\circ} \mathrm{C}$ ). Inset: Calculated quantum efficiencies for the tandem and triple-junction solar cells.

Here, $J_{M}$ and $V_{M}$ are the simulated current density and voltage at the MPP. The subscript $M$ refers to the multijunction cell, and $1,2, \ldots n$ refer to each of its sub-cells. According to the simulated $J-V$ characteristics of the sub-cells in Figure $4 \mathrm{~b}$, our optimized tandem cell has $\Delta \eta=0.28 \%$. This is close to the ideal case for a tandem where $J_{M T}=J_{M 1}=J_{M 2}$, and $V_{M T}=V_{M 1}+V_{M 2}$.

In one further tandem cell structure, we placed the BPhen cathode buffer $(7 \mathrm{~nm}$, below the Ag contact) with the previously described high electron conductivity, exciton blocking BPhen: $\mathrm{C}_{60}(5 \mathrm{~nm}) /$ BPhen $(2 \mathrm{~nm})$ compound electron filter that reduces bimolecular recombination at the buffer/acceptor interface. ${ }^{[26]}$ The electron filter increases $\eta_{\mathrm{p}}$ of the back cell, but also increases the $F F$ and $J_{\mathrm{SC}}$ differences between the sub-cells, which ultimately causes a larger mismatch. The current mismatch results in $\Delta \eta=4.8 \%$, leading to a slight reduction in $J_{\mathrm{SC}}$ $\left(9.0 \pm 0.2 \mathrm{~mA} \mathrm{~cm}^{-2}\right)$ and efficiency $(9.6 \pm 0.2 \%)$ from the tandem in Figure 4. However, the reduced tendency for bimolecular recombination and exciton-polaron quenching suggests that the use of this compound buffer can result in improved response

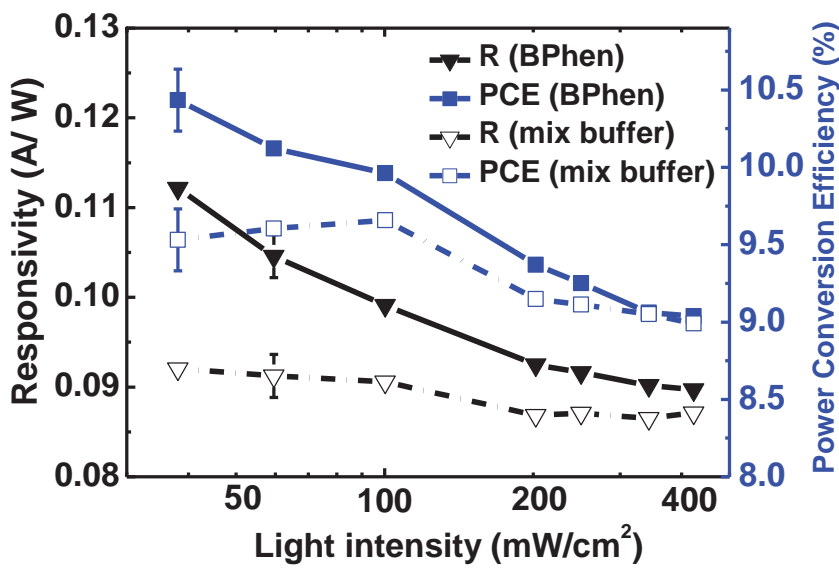

Figure 6. Responsivity $(R)$ and power conversion efficiency $(P C E)$ of the tandem solar cell with BPhen $(7 \mathrm{~nm})$ or BPhen: $C_{60}(1: 1,5 \mathrm{~nm}) /$ BPhen $(2 \mathrm{~nm})$ as the cathode buffer layer as a function of light intensity up to 4 suns, AM 1.5C illumination.

at high intensity ${ }^{[8]}$ Hence, we measured the responsivity and $\eta_{\mathrm{P}}$ from 0.2 sun up to 4 suns intensity of the tandem cells, with BPhen or BPhen: $\mathrm{C}_{60} / \mathrm{BPhen}$ as the cathode buffer layers (see Figure 6). The responsivity of the tandem cell with BPhen decreases from $0.112 \pm 0.002 \mathrm{~A} \mathrm{~W}^{-1}$ to $0.090 \pm 0.002 \mathrm{~A} \mathrm{~W}^{-1}$, while the tandem with the mixed buffer shows only a minor (5\%) change from $0.092 \pm 0.002 \mathrm{~A} \mathrm{~W}^{-1}$ to $0.087 \pm 0.002 \mathrm{~A} \mathrm{~W}^{-1}$. The tandem cell with the mixed cathode buffer shows no efficiency change up to 1 sun intensity, after which it decreases due to series resistance. At 4 suns, both cells exhibit a power conversion efficiency of $9.0 \%$.

The previously reported high efficiency triple-junction cell with $\eta_{\mathrm{p}}=9.6 \%$ divides the back cell of a polymer tandem structure into two thinner sub-cells, ${ }^{[16]}$ which results in a loss in quantum efficiency since the layer thicknesses are limited by solution processing considerations. Vacuum-deposited multijunction cells avoid this problem, allowing for the fabrication of OPVs with an unlimited number of sub-cells. The triplejunction cell has $\Delta \eta \approx 20 \%$, suggesting that as sub-cells are added into the structure, the current mismatch between them increases. Nevertheless, the triple-junction cell has considerable room for efficiency improvements as $\Delta \eta$ is reduced.

In summary, we demonstrated vacuum-deposited small molecule OPVs consisting of two or three PM-HJ sub-cells. The tandem employs two sub-cells with minimally overlapping absorption spectra. In the DTDCTB: $\mathrm{C}_{60}$ front-cell, the CT absorption feature of $\mathrm{C}_{60}$ in the green is suppressed in the 1:1 mixture, enabling the sub-cells to complementarily cover the solar spectrum from $\lambda=350 \mathrm{~nm}$ to $900 \mathrm{~nm}$. The introduction of a transparent BPhen: $\mathrm{C}_{60}$ mixed buffer as the interconnecting blocker layer further reduces the absorption loss, thereby increasing $J_{\mathrm{SC}}$. The optimized tandem exhibits $\eta_{\mathrm{P}}=10.0 \pm$ $0.2 \%$, with $J_{\mathrm{sc}}=9.9 \pm 0.2 \mathrm{~mA} \mathrm{~cm}{ }^{-2}$ under AM $1.5 \mathrm{G}$ one sun illumination (spectrally corrected).

In addition, we fabricated a triple-junction cell by adding an additional DBP: $\mathrm{C}_{70}$ cell as the front sub-cell that absorbs photons in the second order interference maximum. The calculated quantum efficiency is $\approx 100 \%$ at wavelengths between $400 \mathrm{~nm}$ to $700 \mathrm{~nm}$, resulting in $\eta_{\mathrm{P}}=11.1 \pm 0.2 \%$. The multijunction 
OPV consisting of sub-cells with complementary, or non-overlapping spectra, and whose sub-cells are positioned to absorb different optical interference orders, showing potential for future increases in efficiency.

\section{Experimental Section}

Devices were grown on indium tin oxide (ITO, sheet resistance of $15 \Omega /$ sq.) coated glass substrates. All the chemicals were obtained from commercial suppliers: DTDCTB, DBP and BPhen (Luminescence Technology Corp.), $C_{60}$ (MER), $C_{70}$ (SES Research), PTCBI (Sensient) and $\mathrm{MoO}_{3}$ (Alfa Aesar). Prior to use, DTDCTB, DBP, $\mathrm{C}_{60}$ and $\mathrm{C}_{70}$ were purified once using temperature-gradient sublimation. ${ }^{[38]}$

Prior to thin film deposition, the ITO surface was cleaned in a series of detergents and solvents ${ }^{[39]}$ and treated with ultraviolet-ozone for $10 \mathrm{~min}$. All neat films were deposited using vacuum thermal evaporation in a chamber with a base pressure of $\approx 10^{-7}$ Torr at a rate of $0.1 \mathrm{~nm} \mathrm{~s}^{-1}$, except for the $\mathrm{Ag}$ nanoparticle charge recombination layer that was deposited at $0.005 \mathrm{~nm} / \mathrm{s}$. The components of the DTDCTB: $\mathrm{C}_{60}$ and BPhen: $\mathrm{C}_{60}$ layers were co-deposited at $0.1 \mathrm{~nm} \mathrm{~s} \mathrm{~s}^{-1}$, and $\mathrm{DBP}: \mathrm{C}_{70}$ at $0.2 \mathrm{~nm} \mathrm{~s}^{-1}$, with the rate for each material adjusted to achieve the desired volume ratio. The growth rates and thicknesses were monitored using quartz crystal monitors, and calibrated by ex situ variable-angle spectroscopic ellipsometry. The $100 \mathrm{~nm}$ thick Ag cathodes were deposited through a shadow mask with an array of circular, $1 \mathrm{~mm}$ diameter openings that defined the device areas. The device diameters were measured using an optical microscope, and ranged from $0.98 \mathrm{~mm}$ to $1 \mathrm{~mm}$. This $3-4 \%$ device area variation is included in the systematic error calculations.

Following cathode deposition, samples were transferred into a glove box filled with ultrapure $(<0.1 \mathrm{ppm}) \mathrm{N}_{2}$ for testing. The $J-V$ characteristics were obtained for both the single- and multi-junction cells. Measurements were performed vs light intensity using AM 1.5 G solar illumination (ASTM G173-03) from a filtered Xe lamp. Intensities were adjusted using neutral density filters with no dependence on spectrum over the range considered. The cell temperature at 1 sun $\left(1000 \mathrm{~W}-\mathrm{m}^{-2}\right)$ intensity was $25 \pm 1{ }^{\circ} \mathrm{C}$, with a measurement time of $\approx 10 \mathrm{~s}$ to avoid temperature increase. The intensity was measured using a National Renewable Energy Laboratory (NREL) traceable Si reference cell, with $J_{\mathrm{SC}}$ and $\eta_{\mathrm{P}}$ corrected for spectral mismatch. ${ }^{[40]}$ The EQE was measured using monochromated light from a $200 \mathrm{~Hz}$ chopped Xe-lamp whose output was focused to under-fill the device area, and was calibrated with a NIST-traceable Si detector. The spectral mismatch factors $(M)$ for the sub-cells were calculated from the measured responsivities of the samples. Errors in Table 1 correspond to device-to-device variations of $\approx 30$ devices fabricated on a single substrate in the same run, and the measurement of $J_{S C}$ and $\eta_{\mathrm{P}}$ include an additional systematic error of $\approx 5 \%$. Devices reported are from the best substrate samples. Structure optimization and device performance simulations were carried out using the method of Lassiter et al. ${ }^{[31,35]}$

The device response uniformity was measured using a $2 D$ optical scan of a DBP: $C_{70}$ single junction cell at a wavelength of $500 \mathrm{~nm}$. The light from a monochrometer was coupled to the device using an optical fiber with a core diameter of $10 \mu \mathrm{m}$. The current vs fiber position with $\approx 2 \mu \mathrm{m}$ spatial resolution was then used to create a map.

\section{Acknowledgments}

The authors gratefully acknowledge Brian E. Lassiter for providing the tandem simulation code and helpful discussions. This work was partially supported by the Center for Solar and Thermal Energy Conversion at the University of Michigan, a Department of Energy, Energy Frontier Research Center, Award No. DE-SC0000957 (X.X., analysis), the Sun Shot Next Gen II Program of the Department of Energy (X.C., experiment, analysis; S.R.F., analysis), and Nano Flex Power Corp. (J.D.Z. and D.F., analysis).

Received: April 4, 2014

Revised: June 13, 2014

Published online: August 14, 2014

[1] H. Hoppe, N. S. Sariciftci, J. Mater. Res. 2004, 19, 1924

[2] H. Spanggaard, F. C. Krebs, Sol. Energy Mater. Sol. Cells 2004, 83, 125.

[3] S. E. Shaheen, D. S. Ginley, G. E. Jabbour, MRS Bulletin 2005, 30, 10.

[4] C. J. Brabec, Organic photovoltaics: concepts and realization vol. 60. Springer, Berlin 2003.

[5] P. Peumans, A. Yakimov, S. R. Forrest, J. Appl. Phys. 2003, 93, 3693.

[6] P. Peumans, S. Uchida, S. R. Forrest, Nature 2003, 425, 158.

[7] B. P. Rand, J. Genoe, P. Heremans, J. Poortmans, Prog. Photovolt. Res. Appl. 2007, 15, 659.

[8] X. Xiao, K. Bergemann, J. Zimmerman, K. Lee, S. Forrest, Adv. Energy Mater. 2013.

[9] A. K. K. Kyaw, D. H. Wang, D. Wynands, J. Zhang, T.-Q. Nguyen, G. C. Bazan, A. J. Heeger, Nano Lett. 2013, 13, 3796.

[10] D. H. Wang, A. K. K. Kyaw, V. Gupta, G. C. Bazan, A. J. Heeger, Adv. Energy Mater. 2013, 3, 1161.

[11] K. Cnops, B. P. Rand, D. Cheyns, B. Verreet, M. A. Empl, P. Heremans, Nat. Commun. 2014, 5

[12] S. R. Forrest, MRS Bull. 2005, 30, 28.

[13] N. C. Giebink, G. P. Wiederrecht, M. R. Wasielewski, S. R. Forrest, Phys. Rev. B 2011, 83, 195326.

[14] A. Yakimov, S. R. Forrest, Appl. Phys. Lett. 2002, 80, 1667.

[15] J. Xue, S. Uchida, B. P. Rand, S. R. Forrest, Appl. Phys. Lett. 2004, $85,5757$.

[16] W. Li, A. Furlan, K. H. Hendriks, M. M. Wienk, R. A. J. Janssen, J. Am. Chem. Soc. 2013, 135, 5529.

[17] T. Ameri, N. Li, C. J. Brabec, Energy Environ. Sci. 2013, 6, 2390.

[18] J. You, L. Dou, K. Yoshimura, T. Kato, K. Ohya, T. Moriarty, K. Emery, C.-C. Chen, J. Gao, G. Li, Y. Yang, Nat. Commun. 2013, 4, 1446.

[19] Heliatek, http://www.heliatek.com (accessed April 2014).

[20] J. Xue, B. P. Rand, S. Uchida, S. R. Forrest, Adv. Mater. 2005, 17, 66.

[21] X. Xiao, J. D. Zimmerman, B. E. Lassiter, K. J. Bergemann, S. R. Forrest, Appl. Phys. Lett. 2013, 102, 073302.

[22] D. Cheyns, M. Kim, B. Verreet, B. P. Rand, Appl. Phys. Lett. 2014, 104, 093302

[23] S.-W. Chiu, L.-Y. Lin, H.-W. Lin, Y.-H. Chen, Z.-Y. Huang, Y.-T. Lin, F. Lin, Y.-H. Liu, K.-T. Wong, Chem. Commun. 2012, 48, 1857.

[24] L.-Y. Lin, Y.-H. Chen, Z.-Y. Huang, H.-W. Lin, S.-H. Chou, F. Lin, C.-W. Chen, Y.-H. Liu, K.-T. Wong, J. Am. Chem. Soc. 2011, 133, 15822.

[25] Y.-H. Chen, L.-Y. Lin, C.-W. Lu, F. Lin, Z.-Y. Huang, H.-W. Lin, P.-H. Wang, Y.-H. Liu, K.-T. Wong, J. Wen, D. J. Miller, S. B. Darling, J. Am. Chem. Soc. 2012, 134, 13616

[26] A. N. Bartynski, C. Trinh, A. Panda, K. Bergemann, B. E. Lassiter, J. D. Zimmerman, S. R. Forrest, M. E. Thompson, Nano Lett. 2013, 13,3315

[27] S. Kazaoui, N. Minami, Y. Tanabe, H. J. Byrne, A. Eilmes, P. Petelenz, Phys. Rev. B 1998, 58, 7689.

[28] N. Li, B. E. Lassiter, R. R. Lunt, G. Wei, S. R. Forrest, Appl. Phys. Lett. 2009, 94, 023307.

[29] M. Y. Chan, C. S. Lee, S. L. Lai, M. K. Fung, F. L. Wong, H. Y. Sun, K. M. Lau, S. T. Lee, J. Appl. Phys. 2006, 100, 094506.

[30] B. P. Rand, P. Peumans, S. R. Forrest, J. Appl. Phys. 2004, 96, 7519.

[31] B. E. Lassiter, J. D. Zimmerman, A. Panda, X. Xiao, S. R. Forrest, Appl. Phys. Lett. 2012, 101, 063303. 
[32] ASTM G173-03, ASTM International, West Conshohocken, PA 2012.

[33] B. E. Lassiter, J. D. Zimmerman, S. R. Forrest, Appl. Phys. Lett. 2013, 103, 123305.

[34] J. D. Zimmerman, B. E. Lassiter, X. Xiao, K. Sun, A. Dolocan, R. Gearba, D. A. Vanden Bout, K. J. Stevenson, P. Wickramasinghe, M. E. Thompson, S. R. Forrest, ACS Nano 2013, 7, 9268.

[35] B. E. Lassiter, K. C. Renshaw, S. R. Forrest, J. Appl. Phys. 2013, 113, 214505
[36] C. Trinh, K. O. Kirlikovali, A. N. Bartynski, C. J. Tassone, M. F. Toney, G. F. Burkhard, M. D. McGehee, P. I. Djurovich, M. E. Thompson, J. Am. Chem. Soc. 2013, 135, 11920.

[37] Y. Liu, C.-C. Chen, Z. Hong, J. Gao, Y. Yang, H. Zhou, L. Dou, G. Li, Y. Yang, Sci. Rep. 2013, 3, 3356.

[38] S. R. Forrest, Chem. Rev. 1997, 97, 1793.

[39] F. Yang, K. Sun, S. R. Forrest, Adv. Mater. 2007, 19, 4166.

[40] C. H. Seaman, Sol. Energy 1982, 29, 291. 